\title{
Using estrus detection patches to optimally time insemination improved pregnancy risk in suckled beef cows enrolled in a fixed-time artificial insemination program ${ }^{1,2}$
}

\author{
S. L. Hill,* D. M. Grieger,* K. C. Olson,* J. R. Jaeger,* C. R. Dahlen, $\dagger$ G. A. Bridges, $\$$ \\ F. Dantas, \\ E. L. Larimore, || T. L. Steckler, W W. D. Whittier,** J. F. Currin,** and J. S. Stevenson*3 \\ *Department of Animal Sciences and Industry, Kansas State University, Manhattan 66506-0201; \\ $\dagger$ Department of Animal Sciences, North Dakota State University, Fargo 58105; $\$$ North Central Research and \\ Outreach Center, University of Minnesota, Grand Rapids 55744; §Animal and Dairy Sciences, Mississippi State \\ University, Mississippi State 39762; \#Department of Animal Sciences, Colorado State University, Fort Collins \\ 80523; || Department of Animal Sciences, South Dakota State University, Brookings 57007; $\uparrow$ University of Illinois \\ Extension, Simpson 62985; and **Department of Large Animal Clinical Sciences, Virginia Tech, Blacksburg 24061
}

\begin{abstract}
A multilocation study examined pregnancy risk (PR) after delaying AI in suckled beef cows from 60 to $75 \mathrm{~h}$ when estrus had not been detected by $60 \mathrm{~h}$ in response to a 7-d CO-Synch + progesterone insert (CIDR) timed AI (TAI) program (d -7: CIDR insert concurrent with an injection of GnRH; d 0: PGF $_{2 \alpha}$ injection and removal of CIDR insert; and GnRH injection at TAI [60 or $75 \mathrm{~h}$ after CIDR removal]). A total of 1,611 suckled beef cows at 15 locations in 9 states (CO, IL, KS, MN, MS, MT, $\mathrm{ND}, \mathrm{SD}$, and VA) were enrolled. Before applying the fixed-time AI program, BCS was assessed, and blood samples were collected. Estrus was defined to have occurred when an estrus detection patch was $>50 \%$ colored (activated). Pregnancy was determined $35 \mathrm{~d}$ after AI via transrectal ultrasound. Cows $(n=746)$ detected in estrus by $60 \mathrm{~h}(46.3 \%)$ after CIDR removal were inseminated and treated with $\mathrm{GnRH}$ at AI (Control). Remaining nonestrous cows were allocated within location to 3 treatments on the basis of parity and days postpartum: 1) GnRH injection and AI at $60 \mathrm{~h}$ (early-early =EE; $n=292), 2) \mathrm{GnRH}$ injection at
\end{abstract}

$60 \mathrm{~h}$ and $\mathrm{AI}$ at $75 \mathrm{~h}$ (early-delayed $=\mathrm{ED} ; n=282$ ), or 3) $\mathrm{GnRH}$ injection and $\mathrm{AI}$ at $75 \mathrm{~h}$ (delayed-delayed = DD; $n=291)$. Control cows had a greater $(P<0.01)$ $\mathrm{PR}(64.2 \%)$ than other treatments $(\mathrm{EE}=41.7 \%, \mathrm{ED}=$ $52.8 \%, \mathrm{DD}=50.0 \%)$. Use of estrus detection patches to delay AI in cows not in estrus by $60 \mathrm{~h}$ after CIDR insert removal (ED and DD treatments) increased $(P<0.05)$ PR to TAI when compared with cows in the EE treatment. More $(P<0.001)$ cows that showed estrus by $60 \mathrm{~h}$ conceived to $\mathrm{AI}$ at $60 \mathrm{~h}$ than those not showing estrus (64.2\% vs. $48.1 \%)$. Approximately half $(49.2 \%)$ of the cows not in estrus by $60 \mathrm{~h}$ had activated patches by $75 \mathrm{~h}$, resulting in a greater $(P<$ $0.05)$ PR than their nonestrous herd mates in the EE (46.1\% vs. $34.5 \%)$, ED (64.2\% vs. $39.2 \%)$, and DD $(64.8 \%$ vs. $31.5 \%)$ treatments, respectively. Overall, cows showing estrus by $75 \mathrm{~h}(72.7 \%)$ had greater $(P<0.001)$ PR to AI $(61.3 \%$ vs. $37.9 \%)$ than cows not showing estrus. Use of estrus detection patches to allow for a delayed AI in cows not in estrus by $60 \mathrm{~h}$ after removal of the CIDR insert improved PR to TAI by optimizing the timing of the AI in those cows.

Key words: beef cattle, estrus detection, timed AI

(C) 2016 American Society of Animal Science. All rights reserved. J. Anim. Sci. 2016.94:3703-3710 doi:10.2527/jas2016-0469

\footnotetext{
${ }^{1}$ This is contribution number $16-247-\mathrm{J}$ from the Kansas Agricultural Experiment Station.

${ }^{2}$ We gratefully acknowledge many people who assisted with the treatment and care of cows enrolled in this study. We also acknowledge the donations of Factrel, Lutalyse, and CIDR inserts from Roger Saltman, Pfizer Animal Health, New York, NY, and
}

Boyd Dingus, Estrotect, Spring Valley, WI, for supplying the estrus detection patches. We acknowledge Colleen Hill for analyzing progesterone concentrations in blood samples.

${ }^{3}$ Corresponding author: jss@k-state.edu

Received March 14, 2016.

Accepted June 14, 2016. 


\section{INTRODUCTION}

Ovulation control programs are designed to maximize the opportunity for viable sperm and ova to interact in the oviduct after AI in beef cows. In AI systems that allow all cows to be inseminated at a predetermined time (fixed-time AI, TAI), the demand for time conformity of insemination may supersede optimal timing of semen placement relative to estrus or ovulation. Several different strategies have been employed to minimize the difference between actual and optimal timing by examining various single-insemination timings to produce the greatest probability of conception (Busch et al., 2008; Dobbins et al., 2009; Wilson et al., 2010). Allocating cows to optimal fixed times utilizing specific criteria, except for varying the time of AI for all cows (Dobbins et al., 2009), is largely unexplored. Although distribution of ovulation has not been quantified in TAI systems, hours to estrus following $\mathrm{PGF}_{2 \alpha}$ treatments concurrent with progesterone withdrawal has been investigated in the CO-Synch + CIDR program (Busch et al., 2008; Wilson et al., 2010). The reported distribution of estrus (36 through $120 \mathrm{~h}$ after removal of the CIDR insert), in addition to differences in identifiable groups based on parity and estrus-cycle status, indicates that multiple insemination times may increase pregnancy risk (PR) associated with TAI, particularly in heterogeneous groups of cows. The objective of this study was to test the hypothesis that allocating cows into 2 distinct insemination times on the basis of activated estrus detection patches would increase PR.

\section{MATERIALS AND METHODS}

All experimental procedures were approved by the respective Animal Care and Use Committees of the institutions participating in the study.

\section{Experimental Design}

A total of 1,611 mixed-parity beef cows at 15 locations in 9 states (CO, IL, KS, MN, MS, MT, ND, SD, and VA) were enrolled in the experiment. Characteristics of suckled beef cows enrolled by location including breed, percentage of 2-yr-old cows, days postpartum at AI, BCS, and proportion of cows having estrous cycles at the onset of the synchronization program (Table 1). All cows were treated with a 7-d CO-Synch + CIDR program $(100 \mu \mathrm{g}$ GnRH $[2 \mathrm{~mL}$ Factrel, Pfizer Animal Health, Whitehouse Station, NJ] $7 \mathrm{~d}$ before and 60 or $75 \mathrm{~h}$ after $25 \mathrm{mg} \mathrm{PGF}{ }_{2 \alpha}$ [d 0; $5 \mathrm{~mL}$ Lutalyse; Pfizer Animal Health]). A new controlled internal drug release (CIDR) insert (Pfizer Animal Health) containing $1.38 \mathrm{~g}$ progesterone was inserted per vagina at the time of the first GnRH injection (d -7). On d 0, concurrent with removal of the CIDR insert, estrus detection patches (Estrotect, Rockway Inc., Spring Valley, WI) were affixed to the tail head of each cow according to manufacturer's recommendation. Body condition scores $(1=$ thin; 9 = obese; Bellows et al., 1982) were assigned $(d-17)$ before the start of the ovulation synchronization program by a trained evaluator (Fig. 1).

\section{Treatment Assignment}

Estrus detection patches were interpreted and treatment assignments were made at $60 \mathrm{~h}$ after CIDR insert removal. Cows were defined to have exhibited estrus (evidence of standing activity) when $>50 \%$ of the gray coating was rubbed off or when the patch was missing $(<10 \%$ were missing). Cows in estrus by $60 \mathrm{~h}$ had patches removed, received an injection of $100 \mu \mathrm{g}$ $\mathrm{GnRH}$, and were inseminated (Control). Cows within location that had not exhibited estrus by $60 \mathrm{~h}$ were balanced according to days postpartum and parity and then assigned randomly to 3 treatments: 1 ) injected with 100 $\mu \mathrm{g} \mathrm{GnRH}$ and inseminated at $60 \mathrm{~h}$ (early-early; EE), 2) injected with $100 \mu \mathrm{g} \mathrm{GnRH}$ at $60 \mathrm{~h}$ but inseminated at 75 h (early-delayed; ED), or 3) injected with $100 \mu \mathrm{g}$ $\mathrm{GnRH}$ and inseminated at $75 \mathrm{~h}$ (delayed-delayed; DD). At $75 \mathrm{~h}$, all patches were evaluated and removed at $75 \mathrm{~h}$ from EE, ED, and DD cows to determine if estrus had occurred between 60 and 75 h (Fig. 1).

\section{Pregnancy Diagnosis}

Cows were either observed for estrus and inseminated on subsequent estrus or exposed to cleanup bulls beginning 10 to $12 \mathrm{~d}$ after TAI. At $35 \pm 3 \mathrm{~d}$ after TAI, pregnancy was confirmed by transrectal ultrasonography (Aloka 500V, $5 \mathrm{MHz}$ transrectal transducer, Wallingford, CT). A positive pregnancy outcome required presence of a corpus luteum and uterine fluid or an embryo with a heartbeat. A final pregnancy diagnosis was determined via transrectal ultrasonography approximately $35 \mathrm{~d}$ after the end of the breeding season (removal of natural service sires).

\section{Estrus Cycle Status}

Blood samples were collected via puncture of a caudal blood vessel from cows at 10 of the 14 locations on $\mathrm{d}-17$ and -7 . Concentrations of progesterone in serum were measured in duplicate by direct quantitative (nonextracted) RIA using Coat-A-Count progesterone kits (Siemens Medical Solutions Diagnostics, Los Angeles, CA) previously validated for bovine serum (Stevenson et al., 2012). Intra- and interassay CV 
Table 1. Selected characteristics of suckled beef cows enrolled

\begin{tabular}{|c|c|c|c|c|c|c|}
\hline Location $^{1}$ & Breed & $n$ & 2-yr-old cows, $\%$ & Mean $( \pm$ SE) days postpartum at AI & Mean $( \pm$ SE) BCS & Estrus cycle status, ${ }^{2} \%$ \\
\hline$\overline{\mathrm{CO}-1}$ & Angus $\times$ Hereford & 93 & 28 & $74 \pm 1.7$ & $5.8 \pm 0.07$ & $\mathrm{NC}^{3}$ \\
\hline KS-1 & Angus $\times$ Hereford & 178 & 0 & $93 \pm 1.1$ & $5.7 \pm 0.03$ & 96 \\
\hline KS-2 & Angus $\times$ Hereford & 18 & 0 & $74 \pm 3.9$ & $6.4 \pm 0.14$ & 44 \\
\hline KS-3 & Angus $\times$ Hereford & 57 & 0 & $67 \pm 2.9$ & $6.9 \pm 0.11$ & 74 \\
\hline KS-4 & Angus, Hereford, Simmental & 64 & 0 & $75 \pm 1.7$ & $4.8 \pm 0.07$ & 66 \\
\hline KS-5 & Angus $\times$ Hereford & 50 & 20 & $65 \pm 1.6$ & $4.5 \pm 0.06$ & 59 \\
\hline KS-6 & Angus $\times$ Hereford & 29 & 0 & $61 \pm 4.2$ & $6.8 \pm 0.11$ & 59 \\
\hline IL-1 & Angus $\times$ Hereford & 150 & 0 & $67 \pm 1.0$ & $5.2 \pm 0.06$ & $\mathrm{NC}^{3}$ \\
\hline $\mathrm{MN}-1$ & Angus $\times$ Hereford & 125 & 15 & $69 \pm 2.3$ & $4.9 \pm 0.06$ & 61 \\
\hline MS-1 & Angus, Hereford & 50 & 19 & $67 \pm 2.8$ & $5.4 \pm 0.08$ & $\mathrm{NC}^{3}$ \\
\hline MT-1 & Angus & 95 & 35 & $73 \pm 1.6$ & $4.8 \pm 0.08$ & $\mathrm{NC}^{3}$ \\
\hline ND-1 & Angus $\times$ Hereford & 173 & 21 & $71 \pm 0.9$ & $5.4 \pm 0.05$ & $\mathrm{NC}^{3}$ \\
\hline SD-1 & Angus $\times$ Hereford & 102 & 28 & $81 \pm 1.5$ & $5.6 \pm 0.04$ & 32 \\
\hline VA-1 & Angus $\times$ Simmental & 211 & 15 & $79 \pm 1.4$ & $4.5 \pm 0.06$ & 62 \\
\hline VA-2 & Angus $\times$ Simmental & 216 & 16 & $75 \pm 1.2$ & $4.2 \pm 0.04$ & 52 \\
\hline
\end{tabular}

${ }^{1}$ Cows at 15 locations in 9 states were enrolled.

${ }^{2}$ Status was based on progesterone concentrations measured in 2 blood samples collected $10 \mathrm{~d}$ apart before the onset of the experimental protocol. In 4 cows in which pregnancy outcome was determined, blood samples were missing.

${ }^{3} \mathrm{NC}=$ blood samples were not collected to assess estrus cycle status.

for progesterone were $8.9 \%$ and $6.1 \%$, respectively. Assay sensitivity was $14.1 \pm 1.6 \mathrm{pg} / \mathrm{mL}$. Progesterone concentrations were categorized as high $(\geq 1 \mathrm{ng} / \mathrm{mL})$ or low (all other samples). Cows with a high-progesterone status at either $\mathrm{d}-17$ or -7 were defined to have resumed estrous cycles (Table 1). All other cows were considered to have been anestrous at the onset of the ovulation synchronization program.

\section{Statistical Analyses}

The GLIMMIX procedure $($ METHOD = LAPLACE; ILINK $=$ LOGIT DIST $=$ BINOMIAL SOLUTION ODDSRATIO) in SAS (SAS Inst. Inc., Cary, NC) was applied to analyze the binomial outcome variables of estrus cycle status, estrus expression, and PR associated with AI. The independent variables of BCS, days postpartum at AI, and parity (primiparous vs. multiparous) were included as fixed effects in all models. The median value of $\mathrm{BCS}(\mathrm{BCS}=5.0)$ was used to allocate cows into 2 BCS categories ( $<5.0$ vs. $\geq 5.0$ ). Treatment was tested as a fixed effect in the model that examined PR. Significance of treatment was tested by the random effect of treatment within location. Models included interactions of treatment with the fixed effects of parity, BCS, and the continuous variable days postpartum. When no significant interactions with treatment were detected, interactions with treatment were eliminated from the final model. The 2- and 3-way interactions among the variables days postpartum, BCS, and parity were then included in the model. Because a 3-way interaction was detected among parity, BCS, and days postpartum, days postpartum was grouped into quartiles and tested for interactions. Pregnancy risk changed when days postpartum were proportioned at $86 \mathrm{~d}$, resulting in identification of the interaction. A separate model including total expression of estrus (excluded treatment) examined 2-, 3-, and 4-way interactions with BCS, days postpartum, parity, and estrus expression on the dependent variable of PR. No interactions with estrus expression were identified and were therefore removed from the model.

Models to examine expression of estrus were constructed for cows that exhibited estrus by $60 \mathrm{~h}$, between 60 and $75 \mathrm{~h}$, and by $75 \mathrm{~h}$. The general models for estrus at each of the 3 times included estrus cycle status, BCS, and parity. The continuous variable, days postpartum, was converted to a binomial variable by dividing the range of days postpartum at its median ( $<75 \mathrm{vs}$. $\geq 75 \mathrm{~d})$.

Effects of estrus cycle status were not significant when evaluated in any of the 3 models; therefore, estrus cycle status was eliminated to include cows for which that information was not available. The 2- and 3-way interactions of days postpartum, BCS, and parity were included in all estrus expression models. The effect of $\mathrm{GnRH}$ injection timing was evaluated in a model that included estrus expression between 60 and $75 \mathrm{~h}$ as the dependent variable; GnRH injection time of 60 or $75 \mathrm{~h}$ was treated as an independent fixed variable to determine the effect of prior GnRH exposure on subsequent expression of estrus. The GnRH timing model also included BCS, days postpartum, and parity as fixed effects. The random variable location was included as the testing term in all estrus expression models.

A subset of cows for which estrus cycle status information was available was analyzed in a separate GLIMMIX model with estrus cycle status as the 


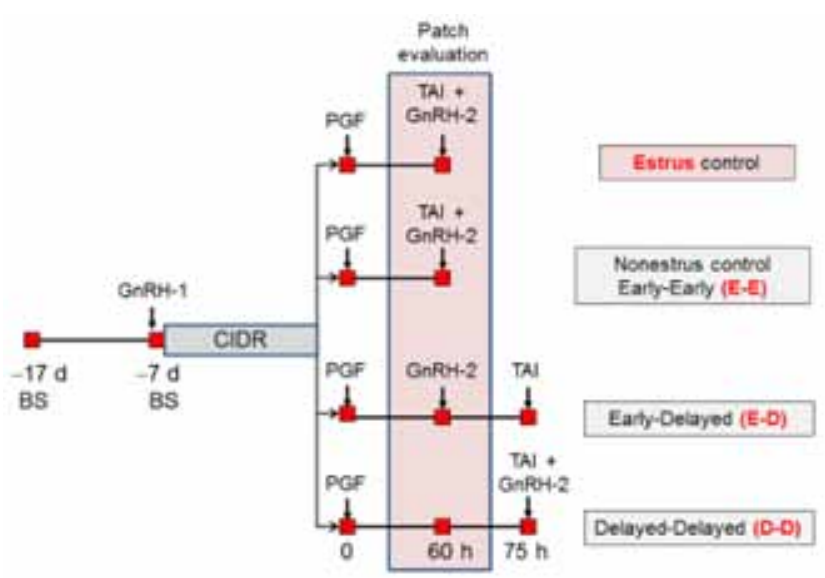

Figure 1. Experimental design of treatments. All cows received an injection of GnRH (GnRH-1) and an intravaginal controlled internal drug release (CIDR) insert containing $1.38 \mathrm{~g}$ of progesterone on study $\mathrm{d}-7$, an injection of $\mathrm{PGF}_{2 \alpha}(\mathrm{PGF})$, and removal of the CIDR insert on $\mathrm{d}$ 0. Estrus detection patches were evaluated at $60 \mathrm{~h}$ to determine treatment allocation (activation was indicated when more than $50 \%$ of the covering material was removed). Cows (control) in estrus by $60 \mathrm{~h}$ had patches removed, received GnRH-2 injection, and were inseminated. Cows within location that had not exhibited estrus by $60 \mathrm{~h}$ were balanced according to days postpartum and parity and assigned randomly to 3 treatments: 1) GnRH-2 injection and AI at $60 \mathrm{~h}$ (early-early; EE), 2) GnRH-2 injection at $60 \mathrm{~h}$ but AI at $75 \mathrm{~h}$ (earlydelayed; ED), or 3) GnRH-2 injection and AI at 75 h (delayed-delayed; DD). Patches in the latter 3 treatments were evaluated and removed at $75 \mathrm{~h}$.

dependent variable. The independent fixed variables (BCS, parity, and days postpartum), all 2-and 3-way interactions among those variables, and the random effect of location were included in the model.

Final pregnancy risk and pregnancy loss (pregnancy loss between TAI and the final pregnancy diagnosis at the end of the breeding season) were both analyzed in models containing treatment or estrus expression and BCS, parity, and days postpartum. In all models differences were determined to be significant when $P \leq 0.05$.

\section{RESULTS}

\section{Pregnancy Risk}

Control cows had a greater $(P<0.01)$ PR than cows in the EE, ED, and DD treatments (Fig. 2). Cows in which AI was performed at $75 \mathrm{~h}$ (ED and DD) had greater $(P<0.05)$ PR than EE cows and did not differ $(P=0.50)$ from one another. The poorest PR was detected in EE cows (not detected in estrus but inseminated and treated with $\mathrm{GnRH}$ at $60 \mathrm{~h}$ ). Cows that were not detected in estrus by $60 \mathrm{~h}$ but expressed estrus by $75 \mathrm{~h}$ (49.2\% of cows not observed in estrus by $60 \mathrm{~h}$ were detected in estrus between 60 and $75 \mathrm{~h}$ ) were more $(P<0.05)$ likely to become pregnant than nonestrous herd mates when they were in the EE $(46.1 \%$ vs. $34.5 \%)$, ED (64.2 vs. $39.2 \%)$, and DD (64.8\% vs. $31.5 \%)$ treatments, respectively. When assessing PR,

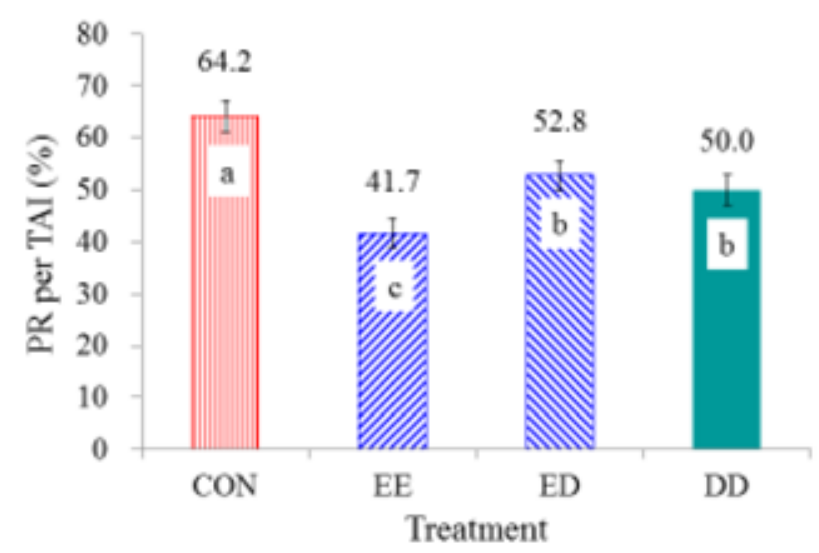

Figure 2. Least squares mean pregnancy risk (PR) per timed AI (TAI) by treatment. Control cows (CON; $n=746)$ were detected in estrus by $60 \mathrm{~h}$, inseminated, and received $\mathrm{GnRH}$ at $60 \mathrm{~h}$. The remaining cows were allocated to 3 treatments: 1) injected with GnRH and inseminated at $60 \mathrm{~h}$ (early-early; $\mathrm{EE} ; n=292), 2$ ) injected with $\mathrm{GnRH}$ at $60 \mathrm{~h}$ but inseminated at $75 \mathrm{~h}$ (earlydelayed; ED; $n=282$ ), or 3) injected with GnRH and inseminated at $75 \mathrm{~h}$ (delayed-delayed; DD; $n=291)$. Bars with different letters differ $(P<0.01)$.

no 2- and 3-way interactions were detected among treatments, BCS, and parity.

Final PR did not differ among treatments, parity, or days postpartum; however, cows with a $\mathrm{BCS} \leq 5$ had lower $(P<0.01)$ PR than cows with a BCS $>5$ (89.5\% vs. $94.1 \%$, respectively). Final PR also was greater $(P=0.001)$ in cows that displayed estrus by either 60 or $75 \mathrm{~h}$ than those that did not display estrus (94.0\% vs. 89.3\%), respectively.

Pregnancy loss in cows pregnant after TAI was $1.3 \% \pm 0.4 \%$. Pregnancy losses associated with treatments (Control, DD, ED, and EE) were 1.0\%, 0.2\%, $2.1 \%$, and $0.4 \%$, respectively. Pregnancy loss was greater $(P=0.04)$ in ED than DD. Pregnancy loss did not differ between parity, estrus expression, days postpartum, or BCS. Furthermore, estrus cycle status before treatments were imposed did not affect pregnancy loss $($ cycling $=1.7 \%$ and not cycling $=1.5 \%)$.

Days postpartum at TAI were analyzed as a covariate in the model describing the effects of treatment on PR. Days postpartum were related positively $(P<0.001)$ with the PR at $35 \mathrm{~d}$ postbreeding, indicating that for every $10-\mathrm{d}$ increase in days postpartum at AI, PR increased by $7.2 \% \pm 1.6 \%$. Pregnancy risk was not affected $(P=$ 0.30 ) by BCS. In contrast, PR in multiparous cows was 1.43 times (adjusted odds ratio $[\mathbf{A O R}]=1.43 ; \mathrm{CI}=1.03$ to 1.98$)$ more likely than in primiparous cows $(56.7 \%$ vs. $47.8 \%$ ). Cows that had resumed estrous cycles before the onset of the breeding season were 1.72 times $(\mathrm{AOR}=1.72 ; \mathrm{CI}=1.29$ to 2.29$)$ more likely to become pregnant to AI than their anestrous herd mates $(60.9 \%$ vs. $47.5 \%$ ). Furthermore, cows detected in estrus by 75 $\mathrm{h}$ were 2.6 times $(\mathrm{AOR}=2.60 ; \mathrm{CI}=1.95$ to 3.46$)$ more likely to become pregnant to AI than their herd mates that did not exhibit estrus (61.3\% vs. $37.9 \%)$. 


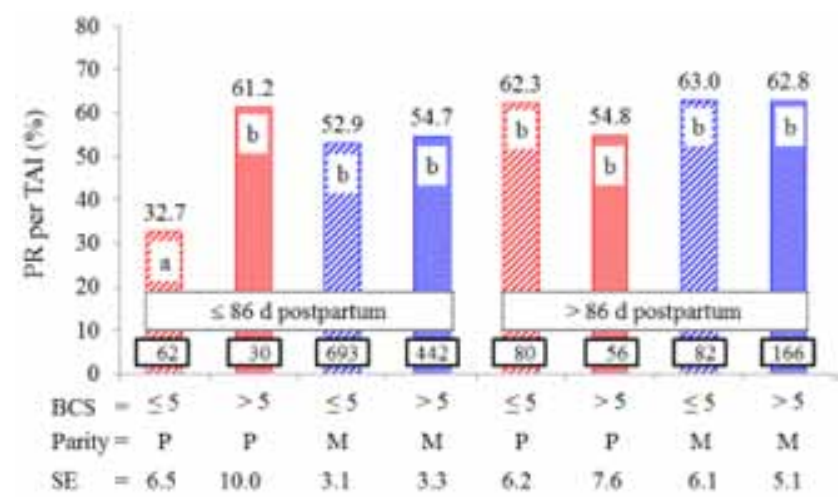

Figure 3. Pregnancy risk (PR) per timed AI (TAI) according to a 3-way interaction among BCS, parity (primiparous $[\mathrm{P}]$ and multiparous $[\mathrm{M}]$ ), and days postpartum at AI. The values at the base of the bars reflect the number of cows in each subgroup. Bars with different letters differ $(P<0.05)$.

Effects of the independent variables, days postpartum, parity, and BCS on PR were analyzed separately, and a 3-way interaction was detected $(P=0.05$; Fig. 3). Pregnancy risk was compromised in primiparous cows in poorer BCS and fewer days postpartum at AI compared with all other variable combinations of days postpartum, BCS, and parity.

\section{Estrus Expression}

A summary of when estrus was expressed (by $60 \mathrm{~h}$ or between 60 and $75 \mathrm{~h}$ ) and the effects of BCS, parity, and days postpartum on expressed estrus is in Table 2 . Overall, $46.3 \%$ of cows showed estrus by 60 h, $49.2 \%$ of the remaining cows showed estrus between 60 and $75 \mathrm{~h}$, and $27.3 \%$ were not detected in estrus by $75 \mathrm{~h}$ after CIDR insert removal. Although days postpartum did not affect the expression of estrus, primiparous, better-conditioned cows were more $(P<0.05)$ likely to display estrus by $60 \mathrm{~h}$ than any other combination of parity and BCS (Table 2).

An interaction between parity and BCS was not detected in cows that displayed estrus between 60 and $75 \mathrm{~h}$ (Table 2). Neither days postpartum nor parity influenced expression of estrus during this 15-h interval, but more $(P<0.05)$ cows in better body condition showed estrus than those with poorer body condition (Table 2).

When estrus was expressed by $75 \mathrm{~h}$, however, more $(P<0.05)$ primiparous cows with BCS $>5$ were detected in estrus compared with all other combinations of parity and BCS (Table 2). Cows with more than $75 \mathrm{~d}$ since calving at AI did not differ $(P>0.49)$ from their herd mates with shorter postpartum intervals in expression of estrus by $75 \mathrm{~h}$ (Table 2).

When comparing occurrence of estrus between 60 and $75 \mathrm{~h}$ in the EE and ED cows, which received $\mathrm{GnRH}$ at $60 \mathrm{~h}$, expression of estrus was not reduced $(P=0.21)$ subsequent to GnRH compared with that of the DD cows that received GnRH at $75 \mathrm{~h}(44.9 \%$ vs.
Table 2. Estrus expression by $60 \mathrm{~h}$, between 60 and $75 \mathrm{~h}$, and by $75 \mathrm{~h}$ after controlled internal drug release insert removal as affected by BCS, parity, and days postpartum

\begin{tabular}{|c|c|c|c|c|c|}
\hline Item & Days postpartum & BCS & Parity & $n$ & Estrus, $\%$ \\
\hline \multicolumn{6}{|l|}{ Estrus by $60 \mathrm{~h}$} \\
\hline \multirow[t]{2}{*}{ Days postpartum } & $\leq 75$ & - & - & 773 & 48.3 \\
\hline & $>75$ & - & - & 838 & 44.5 \\
\hline \multirow[t]{4}{*}{$\mathrm{BCS} \times$ parity } & - & $>5$ & 1 & 86 & $65.1^{\mathrm{a}}$ \\
\hline & - & $\leq 5$ & 1 & 142 & $46.5^{\mathrm{b}}$ \\
\hline & - & $>5$ & $2+$ & 608 & $48.8^{\mathrm{b}}$ \\
\hline & - & $\leq 5$ & $2+$ & 775 & $42.2^{\mathrm{b}}$ \\
\hline \multicolumn{6}{|c|}{ Estrus between 60 and $75 \mathrm{~h}$} \\
\hline \multirow[t]{2}{*}{ Days postpartum } & $\leq 75$ & - & - & 400 & 51.0 \\
\hline & $>75$ & - & - & 465 & 47.7 \\
\hline \multirow[t]{2}{*}{$\mathrm{BCS}$} & - & $>5$ & - & 341 & $51.9^{\mathrm{a}}$ \\
\hline & - & $\leq 5$ & - & 524 & $47.5^{\mathrm{b}}$ \\
\hline \multirow[t]{2}{*}{ Parity } & - & - & 1 & 106 & 46.2 \\
\hline & - & - & $2+$ & 759 & 49.7 \\
\hline $\mathrm{GnRH}$ at $60 \mathrm{~h}$ & - & - & - & 574 & 47.7 \\
\hline GnRH at $75 \mathrm{~h}$ & - & - & - & 291 & 52.2 \\
\hline \multicolumn{6}{|l|}{ Estrus by $75 \mathrm{~h}$} \\
\hline \multirow[t]{2}{*}{ Days postpartum } & $\leq 75$ & - & - & 773 & 74.6 \\
\hline & $>75$ & - & - & 838 & 71.0 \\
\hline \multirow[t]{4}{*}{$\mathrm{BCS} \times$ parity } & - & $>5$ & 1 & 86 & $84.9^{\mathrm{a}}$ \\
\hline & - & $\leq 5$ & 1 & 142 & $69.0^{\mathrm{b}}$ \\
\hline & - & $>5$ & $2+$ & 608 & $75.2^{\mathrm{c}}$ \\
\hline & - & $\leq 5$ & $2+$ & 775 & $70.2^{\mathrm{b}, \mathrm{c}}$ \\
\hline
\end{tabular}

49.5\%). Furthermore, for cows not detected in estrus between 60 and $75 \mathrm{~h}$ but inseminated at $75 \mathrm{~h}, \mathrm{PR}$ did not differ $(P=0.25)$ between cows receiving GnRH at 60 and 75 h (46.0\% vs. $39.1 \%)$.

\section{Estrus Cycle Status}

In a subset of cows $(n=1,046)$ factors affecting estrus cycle status at the beginning of the breeding season were analyzed. When all 2-way interactions among $\mathrm{BCS}$, days postpartum, and parity were tested, an interaction of magnitude was detected between BCS and days postpartum. The combination of $>75 \mathrm{~d}$ postpartum and BCS $>5$ resulted in greater $(P<0.006)$ estrous cyclicity $(78.2 \%)$ than the combinations of $>75 \mathrm{~d}$ postpartum and $\mathrm{BCS} \leq 5(59.6 \%), \leq 75 \mathrm{~d}$ postpartum and $\mathrm{BCS}$ $>5(48.4 \%)$, or $\leq 75 \mathrm{~d}$ postpartum and $\mathrm{BCS} \leq 5(54.9 \%)$. The proportion of primiparous and multiparous cows having resumed estrous cycles before AI did not differ $(P=0.37 ; 64.4 \%$ vs. $57.7 \%)$, respectively.

\section{DISCUSSION}

Fixed-time AI is a strategy to reduce the variation in the timing of ovulation among females to maximize fertility after a single AI. Reproductive strategies that 
employ $\mathrm{PGF}_{2 \alpha}, \mathrm{GnRH}$, and progestins have reduced the distribution of estrus in populations of cows subjected to AI compared with using no synchronization program. Ovulation after estrus is reported to be $31 \pm 0.6 \mathrm{~h}$ in beef cows (White et al., 2002). The distribution of ovulation in beef cows exposed to a TAI system has not been quantified; however, numerous studies have shown increased proportion of cows becoming pregnant after TAI when they exhibit estrus at or before time of GnRH to induce ovulation (Perry et al., 2005; Busch et al., 2008; Hill et al., 2014). Perry et al. (2005) also reported that cows exhibiting estrus had greater subsequent concentrations of circulating estradiol and greater subsequent concentration of progesterone than nonestrous cows. Increasing the number of beef cows in estrus at the same time also increased the number of times each cow was mounted and the duration of estrus (Floyd et al., 2009) and may increase the possibility of identifying more cows with less overt estrus expression to inseminate them at a more ideal time in a split-time AI program.

Increased proportion of cows displaying estrus and becoming pregnant also is associated with greater conceptus size at $d 19$ of pregnancy and greater abundance of transcriptions for proteins in the endometrium that are favorable to pregnancy (Davoodi et al., 2016). Heifers inseminated after expressing estrus also had higherquality embryos at a more advanced physiological stage than heifers not expressing estrus (Larimore et al., 2015). Acidification of the uterus ( $\mathrm{pH} 7.0$ to 6.7) occurs in cows that express estrus (Perry and Perry, 2008a,b), and prolonged viability of sperm has been associated with decreased intracellular sperm pH (Jones and Bavister, 2000).

It is clear that the uterine environment and endocrine milieu are more suitable for fertilization and embryo development in cows that express estrus when compared with those that do not. Recent research in beef cattle induced to ovulate immature follicles indicates that deficient uterine function is a major factor responsible for infertility in these cows (Bridges et al., 2013). Failure to produce adequate concentrations of estradiol before ovulation results in delayed effects of expression and localization of uterine genes and proteins that participate in regulating uterine functions during early gestation (Bridges et al., 2013).

Pregnancy risk was consistently greater in cows that expressed estrus up through $75 \mathrm{~h}(64.2 \%$ to $64.8 \%)$ except for the lower PR (46\%) in the EE cows that expressed estrus. This lower PR could be attributed to GnRH induction of smaller follicles lacking insufficient estradiol to induce sexual behavior and estrus by $60 \mathrm{~h}$ but did not reduce subsequent estrus expression compared with cows that received GnRH at $75 \mathrm{~h}$. In contrast, the ED cows expressing estrus also received GnRH at $60 \mathrm{~h}$ but had greater pregnancy risk. Therefore, lack of subse- quent estradiol production and estrus may not explain the poorer PR, rather the timing of the insemination or insufficient uterine function because of inadequate estradiol associated with estrus expression (Bridges et al., 2013).

The classic work reported by Saacke (2008) illustrates the importance of insemination timing relative to the onset of estrus. In those studies, cows inseminated near the onset of estrus tended to have lower fertilization risk but greater embryonic quality compared with cows inseminated $24 \mathrm{~h}$ after the onset of estrus, in which fertilization risk was greater but embryo quality was compromised. Therefore, Saacke (2008) concluded that inseminating cows according the traditional a.m.-p.m. rule is a compromise to achieve maximal fertilization success and maintain embryo quality compared with inseminating very early or very late relative to the onset of estrus.

In light of those conclusions, perhaps the poorer PR in EE cows inseminated at $60 \mathrm{~h}$ was similar to PR in cows in which inseminations were made early in estrus that resulted in lower fertilization risk but greater embryo quality than that for ED cows, resulting in the difference in PR being related to more fertilization failure in the $\mathrm{EE}$ cows. Compared with beef heifers not exhibiting estrus before TAI, however, heifers that expressed estrus had improved embryo quality and advanced embryo stage on d 6 and increased the number of accessory sperm associated with the embryo (Larimore et al., 2015). Therefore, differences in PR between the EE and ED cows, which exhibited estrus, may be attributed to differences in uterine environment, fertilization risk, or embryo quality.

Strategies to increase the proportion of cows in estrus exposed to TAI systems may be valuable; however, the actual expression of estrus (79\% to $85 \%$ ) reported previously (Wilson et al., 2010) during 36 through $144 \mathrm{~h}$ after $\mathrm{PGF}_{2 \alpha}$ indicates that strategies to more closely synchronize estrus or ovulation and timing of insemination may have the greatest opportunity for success. In the current study we observed more than $75 \%$ of cows exhibiting estrus by $75 \mathrm{~h}$ after removal of the CIDR insert and $\mathrm{PGF}_{2 \alpha}$ injection, regardless of estrus cycle status, parity, or days postpartum. The recommended optimal insemination time of $66 \mathrm{~h}$ after CIDR removal is not ideal for up to $53.7 \%$ of the cows in the present study that had not displayed estrus by $60 \mathrm{~h}$. The results of the current study indicate that primiparous cows display estrus earlier than multiparous cows. This observation corroborates results of an earlier study (Dobbins et al., 2009) in which younger cows were more fertile when inseminated at an earlier fixed time $(\leq 56 \mathrm{~h}$ after removal of the CIDR insert) than multiparous cows. A possible bimodal distribution of estrus between primiparous and multiparous cows indicates that insemination at 2 distinct times determined by estrus detection would result in more cows being inseminated after estrus expression. 
The distribution of estrus in cows reported elsewhere (Wilson et al., 2010) indicated that approximately 50\% of cows exhibited estrus by $60 \mathrm{~h}$ after CIDR removal. We chose $60 \mathrm{~h}$ as the timing of the first AI and observed that $46 \%$ of cows expressed estrus by $60 \mathrm{~h}$. We chose 75 $\mathrm{h}$ after CIDR insert removal for the second AI time to coincide with the 12- to 16-h interval from beginning of estrus expression to maximum conception risk in dairy cows (Stevenson et al., 2014). Although estrus expression by $75 \mathrm{~h}$ was not influenced by days postpartum, indicating that progestin-based synchronization programs are effective at inducing estrus and presumably ovulation in noncycling cows, parity-BCS interactions were detected, with better-conditioned primiparous cows having the greatest expression by $75 \mathrm{~h}$. All cows that expressed estrus preceding AI had greater PR than their nonestrous herd mates, indicating that regardless of insemination time, it was preferable to inseminate after estrus. The EE cows that were inseminated at $60 \mathrm{~h}$ had lower PR than any other treatment, despite receiving GnRH before AI. Timing of GnRH injection at either 60 or $75 \mathrm{~h}$ did not affect either subsequent estrus expression or PR, indicating some flexibility in applying these procedures in commercial operations. The GnRH injection concurrent with insemination may be unnecessary in single fixed-time AI systems when estrus is detected (Perry and Perry, 2009). The importance of concurrent GnRH injection in cows displaying estrus has not been tested in a split timed AI system; however, increasing the number of cows inseminated after estrus has the potential to reduce the reliance on induced ovulation via exogenous $\mathrm{GnRH}$ treatment.

In a similarly conducted study in cows utilizing sex-sorted semen, increases in PR were noted when utilizing 2 AI times (Thomas et al., 2014a). In another study examining 2 AI times with conventional semen, no difference in PR was detected between early and later inseminated nonestrous cows (Thomas et al., 2014b). It is likely that the difference in results noted between the latter study and the current study is the choice of insemination times relative to removal of the CIDR insert. In the current study, it is probable that the second insemination was closer to the optimal time between semen placement and ovulation for cows that exhibited estrus between 60 and $75 \mathrm{~h}$ when compared with the second insemination timing of $86 \mathrm{~h}$ in the previous report (Thomas et al., 2014b).

In summary, delaying the insemination of cows to $75 \mathrm{~h}$ when not detected in estrus by $60 \mathrm{~h}$ increased the PR compared with that of like cows inseminated at 60 $\mathrm{h}$ regardless of whether $\mathrm{GnRH}$ was injected at 60 or $75 \mathrm{~h}$. By delaying insemination of nonestrous cows to $75 \mathrm{~h}$, the number of cows inseminated after exhibiting estrus was increased. Pregnancy risk was consistently greater in cows that had displayed estrus before TAI.

\section{LITERATURE CITED}

Bellows, R. A., R. E. Short, and G. V. Richardson. 1982. Effects of sire, age of dam and gestation feed level on dystocia and postpartum reproduction. J. Anim. Sci. 55:18-27.

Bridges, G. A., M. L. Day, T. W. Geary, and L. H. Cruppe. 2013. Deficiencies in the uterine environment and failure to support embryonic development. J. Anim. Sci. 91:3002-3013. doi:10.2527/jas.2013-5882

Busch, D. C., D. J. Schafer, D. J. Wilson, D. A. Mallory, N. R. Leitman, J. K. Haden, M. R. Ellersieck, M. F. Smith, and D. J. Patterson. 2008. Timing of artificial insemination in postpartum beef cows following administration of the CO-Synch + controlled internal drug release protocol. J. Anim. Sci. 86:1519-1525. doi:10.2527/ jas.2008-0925

Davoodi, S., R. F. Cooke, A. C. C. Fernandes, B. I. Cappellozza, J. L. M. Vasconcelos, and R. L. A. Cerri. 2016. Expression of estrus modifies the gene expression profile in reproductive tissues on day 19 of gestation in beef cows. Theriogenology 85:645-655. 10.1016/j.theriogenology.2015.10.002

Dobbins, C. A., D. R. Eborn, D. E. Tenhouse, R. M. Breiner, S. K. Johnson, T. T. Marston, and J. S. Stevenson. 2009. Insemination timing affects pregnancy rates in beef cows treated with COSynch protocol including an intravaginal progesterone insert. Theriogenology 72:1009-1016. doi:10.1016/j.theriogenology.2009.06.025

Floyd, L. N., C. A. Lents, F. J. White, and R. P. Wettemann. 2009. Effect of number of cows in estrus and confinement area on estrous behavior of beef cows. J. Anim. Sci. 87:1998-2004. doi:10.2527/jas.2008-1380

Hill, S. L., G. A. Perry, V. R. Mercadante, G. C. Lamb, J. R. Jaeger, K. C. Olson, and J. S. Stevenson. 2014. Altered progesterone concentrations by hormonal manipulations before a fixed-time artificial insemination CO-Synch + CIDR program in suckled beef cows. Theriogenology 82:104-113. doi:10.1016/j.theriogenology.2014.03.008

Jones, J. M., and B. D. Bavister. 2000. Acidification of intracellular $\mathrm{pH}$ in bovine spermatozoa suppresses motility and extends viable life. J. Androl. 21:616-624.

Larimore, E. L., O. L. Amundson, S. L. Bird, B. J. Funnell, S. G. Kruse, G. A. Bridges, and G. A. Perry. 2015. Influence of estrus at fixed-time artificial insemination on early embryonic development in beef cattle. J. Anim. Sci. 93:2806-2812. doi:10.2527/ jas.2015-8892

Perry, G. A., and B. L. Perry. 2008a. Effect of preovulatory concentrations of estradiol and initiation of standing estrus on uterine $\mathrm{pH}$ in beef cows. Domest. Anim. Endocrinol. 34:333-338. doi:10.1016/j.domaniend.2007.09.003

Perry, G. A., and B. L. Perry. 2008b. Effects of standing estrus and supplemental estradiol on changes in uterine $\mathrm{pH}$ during a fixedtime artificial insemination protocol. J. Anim. Sci. 86:29282935. doi: $10.2527 /$ jas.2008-1181

Perry, G. A., and B. L. Perry. 2009. GnRH treatment at artificial insemination in beef cattle fails to increase plasma progesterone concentrations or pregnancy rates. Theriogenology 71:775-779. doi:10.1016/j.theriogenology.2008.09.050

Perry, G. A., M. F. Smith, M. C. Lucy, J. A. Green, T. E. Parks, M. D. MacNeil, A. J. Roberts, and T. W. Geary. 2005. Relationship between follicle size at insemination and pregnancy success. Proc. Natl. Acad. Sci. U.S.A. 102:5268-5273. doi:10.1073/ pnas.0501700102

Saacke, R. G. 2008. Insemination factors related to timed AI in cattle. Theriogenology 70:479-484. doi:10.1016/j.theriogenology.2008.04.015 
Stevenson, J. S., S. L. Hill, R. L. Nebel, and J. M. DeJarnette. 2014. Ovulation timing and conception risk after automated activity monitoring in lactating dairy cows. J. Dairy Sci. 97:4296-4308. doi:10.3168/jds.2013-7873

Stevenson, J. S., S. L. Pulley, and H. I. Mellieon Jr. 2012. Prostaglandin $\mathrm{F}_{2 \alpha}$ and gonadotropin-releasing hormone administration improve progesterone status, luteal number, and proportion of ovular and anovular dairy cows with corpora lutea before a timed artificial insemination program. J. Dairy Sci. 95:1831-1844. doi:10.3168/jds.2011-4767.

Thomas, J. M., S. L. Lock, S. E. Poock, M. R. Ellersieck, M. F. Smith, and D. J. Patterson. 2014a. Delayed insemination of nonestrous cows improves pregnancy rates when using sex-sorted semen in timed artificial insemination of suckled beef cows. J. Anim. Sci. 92:1747-1752. doi:10.2527/jas.2013-7131
Thomas, J. M., S. E. Poock, M. R. Ellersieck, M. F. Smith, and D. J. Patterson. 2014b. Delayed insemination on non-estrous heifers and cows when using conventional semen in artificial insemination. J. Anim. Sci. 92:4189-4197. doi:10.2527/jas.2014-7827

White, F. J., R. P. Wettemann, M. L. Looper, T. M. Prado, and G. L. Morgan. 2002. Seasonal effects on estrous behavior and time of ovulation in nonlactating beef cows. J. Anim. Sci. 80:30533059.

Wilson, D. J., D. A. Mallory, D. C. Busch, N. R. Leitman, J. K. Haden, D. J. Schafer, M. R. Ellersieck, M. F. Smith, and D. J. Patterson. 2010. Comparison of short-term progestin-based protocols to synchronize estrus and ovulation in postpartum beef cows. J. Anim. Sci. 88:2045-2054. doi:10.2527/jas.2009-2627 